ISSN 0258-7122 (Print), 2408-8293 (Online)

Bangladesh J. Agril. Res. 42(3): 503-508, September 2017

\title{
MATING, OVIPOSITION BEHAVIOUR AND BIOLOGY OF HOGPLUM BEETLE
}

\begin{abstract}
M. M. H. KHAN ${ }^{1}$
Abstract

Experiments were conducted to observe mating and oviposition behabiour as well as biology of hog-plum beetle. Results revealed that the average mating frequency, mating duration and mating interval were 11.2, 30.5 hours and 60.3 hours, respectively. The highest number of eggs per clusters was on leaf rachis followed by young stem. The mean number of eggs per cluster was 15.70 while the length and breadth of an egg was $1.95 \mathrm{~mm}$ and $0.60 \mathrm{~mm}$, respectively. The mean duration of $1^{\text {st }}, 2^{\text {nd }}, 3^{\text {rd }}$ and $4^{\text {th }}$ instar larvae were $3.80,3.40,3.70$ and 3.00 days, respectively. The mean pupal period was 22.74 days. The female beetle lived longer (48.30 days) than the male (45.10 days). The size of female beetle was larger $(15.30 \mathrm{~mm})$ than male $(11.96 \mathrm{~mm})$. The mean length of antennae was $7.42 \mathrm{~mm}$. The length of fore, mid and hind legs were $9.20,9.50$ and $11.70 \mathrm{~mm}$, respectively. Hind wings were larger (16.10 mm length and $7.85 \mathrm{~mm}$ breadth) than fore wings (12.38 mm length and $5.30 \mathrm{~mm}$ breadth).
\end{abstract}

Keywords: Biology, mating, morphometrics, oviposition, Podontia 14-punctata.

\section{Introduction}

The hog-plum is a deciduous perennial tree with thick succulent leaves. It is very popular fruit in Bangladesh and it grows all over the country. But the quality fruits are produced only in the southern districts especially in Barisal and Patuakhali (Sarder and Mondal, 1983). Its cultivation is seriously hampered by hog-plum beetle or fourteen spotted leaf beetle Podontia 14-punctata L. (Chrysomelidae: Coleopteran). The fourteen spotted leaf beetle is distributed throughout South East Asia (Husain and Ahmed, 1977; Howlader, 1993). Mondal (1975) reported that insect appeared in large number during the month from May to June. In Bangladesh, the beetles appear in June, abundant during July to September and disappear in October. The beetles cause serious damage to hog-plum from July to August and the peak defoliation occurred during August to September (Mondal, 1975; Baksha, 1997). Both adults and grubs of this beetle feed on the leaves of the hog-plum and heavy infestation often cause complete defoliation of the tree (Ahmed, 1969; Mondal, 1975; Sarder and Mondal, 1983). Sarder and Mondal (1983) found that the mating of hog-plum beetle took place 2-3 weeks after adult emergence. At the beginning of the mating, the male generally takes initiative and become very aggressive. The males become heated and sometimes moves around the female until they are attracted her for mating.

${ }^{1}$ Department of Entomology, Patuakhali Science and Technology University, Dumki, Patuakhali-8602, Bangladesh. 
The male gets on the back of the female and remains at an angle of $60^{\circ}$, fixing posterior end with the female and start mating. The female also helps in doing so. During mating they cannot fly. Mating generally commenced from the early morning and lasted for 3 to 6 hours. The knowledge of biology of any insect pest helps in developing sound management techniques. Considering the above facts, the research was undertaken to know the mating, oviposition behavior and biology of hog-plum beetle.

\section{Materials and Method}

The study was carried out in the laboratory of the Department of Entomology, Patuakhali Science and Technology University (PSTU), Dumki, Patuakhali during April to September, 2012. The experiment was done at normal room temperature, $32 \pm 2{ }^{\circ} \mathrm{C}$ and relative humidity $(85 \pm 5 \%)$ with a $14 \pm 2: 10 \pm 2$ light and dark cycle (L: D).

Observation of Mating and oviposition behavior: Ten pairs of healthy adult beetles were collected from hog-plum trees in couples at mating condition in the morning. After collecting, each couple was released in a separate plastic box $(26.6 \times 14.2 \times 12.2 \mathrm{~cm})$ provided with a fresh hog-plum leaflet by wrapping the base of leaflet with cotton soaked in $1 \%$ sugar solution. The mouth of each box was covered with nylon net ( 25 mesh) by using rubber band. The fed leaflets were replaced by fresh ones daily and plastic box was cleaned by removing excreta to ensure healthy environment inside the box. Data on the time of beginning and end of mating, mating frequency from 7.00 AM to $10 \mathrm{PM}$, duration of each mating, interval of mating and oviposition activity were recorded by close observation. The number of eggs per cluster and total number of clusters laid by individual female were counted from different plant parts of hog-plum under natural condition by covering the couple with nylon net.

Observation of developmental stages: Fifty newly hatched larvae were collected from hog-plum trees planted in the hog-plum orchard at Rahamatpur of Barisal district. The newly hatched larvae were yellowish in colour with prominent large black head. Gradually the colour changed to grayish colour following the feeding on hog-plum leaves. After collecting, five newly hatched larvae were placed in a plastic box containing fresh hog-plum leaflets. The larvae were examined daily for larval moults. The second instar larvae came out leaving their exuvae. Before moulting the larvae stopped feeding and remained inactive. Fresh hog-plum leaflets were supplied to replace the used ones regularly till pupation. Developmental period of $1^{\text {st }}$ instar larvae was measured by the time elapsed between egg hatching to $1^{\text {st }}$ moulting. In this way the duration of $2^{\text {nd }}, 3^{\text {rd }}$ and $4^{\text {th }}$ (final) instars were recorded. A small quantity of sand mixed with soil was placed at the bottom of the box for pupation. Pupal period was also calculated by the time interval between cessation of feeding and hiding inside the soil for pupation. The longevity of adult male and female beetles was recorded. 
Morphometrics of larvae and adult: To find out the length and head width (mm) of different larval instars were measured using a mm scale. Mean values of larval length $(\mathrm{mm})$ and head width $(\mathrm{mm})$ were based on ten observations. Similarly, the length and breadth of adult male and female beetles were measured. For this, ten observations, each for male and female adults were taken. Data on the morphometric measurements of larvae, adult, antennae, legs and wings were made. The weight of full grown larva, adult male and female was measured by using an electric balance. Means and standard errors (SE) were calculated from ten observations.

\section{Results and Discussion}

The frequency of mating of 10 couples ranged from 7 to 15 times with mean frequency 11.2 times. Similarly, the duration of mating of 10 couples ranged from 27 to 34 hours with mean duration 30.5 hours. The interval of mating among 10 couples ranged from 57 to 64 hours with mean duration 60.3 hours(Fig. 1). The findings of the present study are in similar trend with findings of Uddin et al. (2014) who observed highest frequency of mating 14 times, duration of mating 33 hours and mating interval 63 hours by using 10 couples.

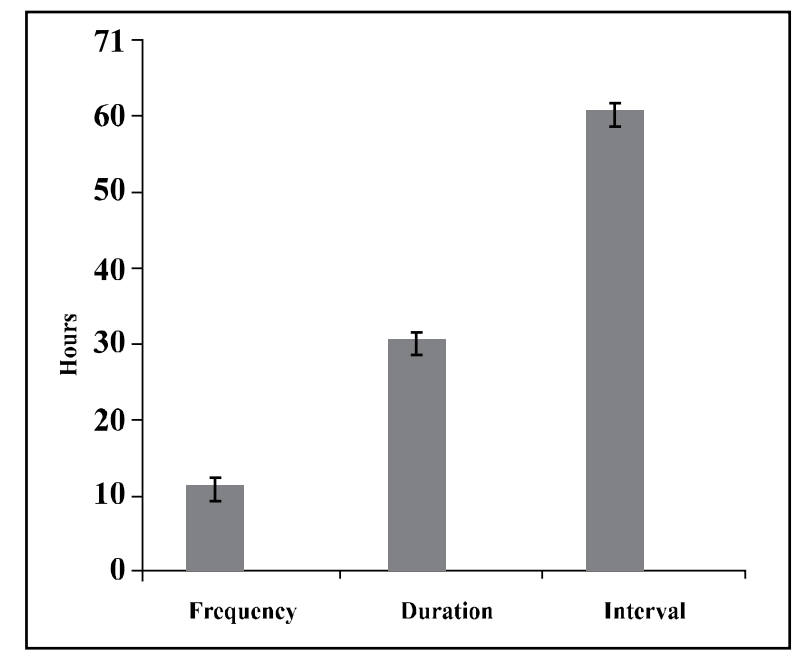

Fig. 1. Mating performances of hog-plum beetle.

In case of leaf, most of the couples laid eggs in clusters on dorsal side $(1.57 \pm$ $0.31)$ and leaf rachis along with young stem $(2.1 \pm 0.35)$ of the leaf but only very few clusters were laid on ventral side $(1.3 \pm 0.00)$ of the leaf (Fig. 2). From the results it is clear that the maximum egg laying tendency of $P$. 14- punctata was on the leaf rachis along with young stem. Ventral leaf surface was less preferred for laying egg and dorsal side was intermediate preferred. Mondal (1975) observed that female beetles preferably choose stem and bark of the plant near leaves for egg laying. Because heavy bodied adult female probably feel comfortable to lay their eggs on stem and bark. Moreover, females of the second 
or latter generations do not get enough leaves because of the complete defoliation. In case of branch, the number of egg clusters per branch ranged 5-9 with mean 6.40 and standard error 0.03 (Fig. 2). The findings are supported by Uddin et al. (2014). The observation of Baksha (1997), Singh and Misra (1989) on these behavioural parameters supported the findings of the present study.

Developmental periods of different stages of hog-plum beetle are presented in Figure 3. The mean duration of $1^{\text {st }}$ and $2^{\text {nd }}$ instar larvae was $3.80 \pm 0.21$ days and $3.40 \pm 0.11$ days, respectively. The mean duration of $3^{\text {rd }}$ and $4^{\text {th }}$ instar larvae was $3.70 \pm 0.21$ days and $3.00 \pm 0.28$ days, respectively. The mean pupal period was $22.74 \pm 0.56$ days. The mean duration of adult male and adult female was 45.10 \pm 3.23 days and $48.30 \pm 1.10$ days, respectively. The findings are also supported by Uddin et al. (2014).

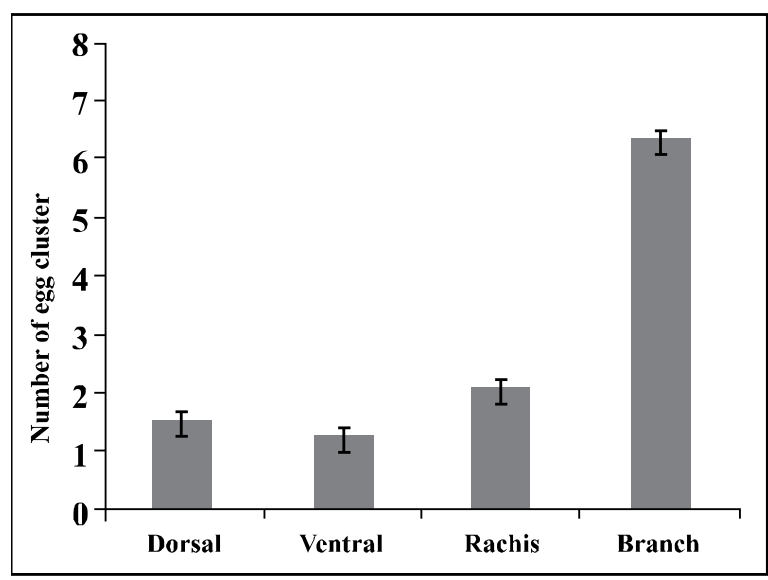

Fig. 2. Oviposition behaviour (number of egg cluster deposited) of hog-plum beetle on leaf surface (dorsal and ventral), leaf rachis and branch of hog-plum tree.

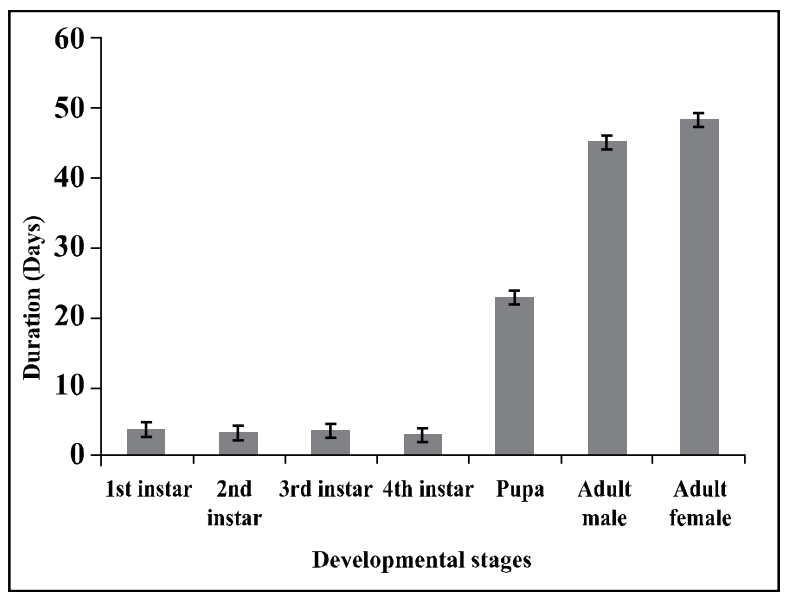

Fig. 3. Duration of different developmental stages of hog-plum beetle under laboratory condition. 
The mean length and breadth of egg were $1.95 \pm 0.02 \mathrm{~mm}$ and $0.60 \pm 0.01 \mathrm{~mm}$, respectively.

The mean length and head width of first instar larvae were $2.51 \pm 0.18 \mathrm{~mm}$ and $0.72 \pm 0.00 \mathrm{~mm}$, respectively. The mean length of the $2^{\text {nd }}$ instar larvae was $8.27 \pm$ $0.20 \mathrm{~mm}$ and the mean head width was $1.54 \pm 0.05 \mathrm{~mm}$. The mean length of the 3rd instar larvae was $16.02 \pm 0.23 \mathrm{~mm}$ with mean head width was $2.31 \pm 0.04$ $\mathrm{mm}$. The mean length and head width of $4^{\text {th }}$ instar larvae were $21.80 \pm 0.51 \mathrm{~mm}$ and $2.81 \pm 0.10 \mathrm{~mm}$, respectively. The mean length of male beetle was $11.96 \pm$ $0.15 \mathrm{~mm}$ with a mean breadth (across thorax) was $6.1 \pm 0.05 \mathrm{~mm}$. The mean length of female beetle was $15.31 \pm 0.16 \mathrm{~mm}$ with a mean breadth (across thorax) was $8.25 \pm 0.21 \mathrm{~mm}$ (Table 1 ).

Similarly, the mean length of the antennae was $7.42 \pm 0.20 \mathrm{~mm}$. The mean length of fore, middle and hind legs was $9.20 \pm 0.23 \mathrm{~mm}, 9.50 \pm 0.24 \mathrm{~mm}$ and $11.70 \pm$ $0.15 \mathrm{~mm}$, respectively. The mean length of fore (elytra) and hind wings were $12.38 \pm 0.16 \mathrm{~mm}$ and $16.10 \pm 0.26 \mathrm{~mm}$, respectively. The hind wings were longer by about $4 \mathrm{~mm}$ than the fore wings in length (Table 1). The mean width of fore and hind wings were $5.30 \pm 0.14 \mathrm{~mm}$ and $7.85 \pm 0.41 \mathrm{~mm}$, respectively. Similarly, the hind wings were broader by about $2 \mathrm{~mm}$ than the fore wings in breadth (Table 1). According to Mondal (1975) the $1^{\text {st }}$ instar larvae measured $3.53 \mathrm{~mm}$ in length and $0.73 \mathrm{~mm}$ in head width. The larval length and head width of the $2^{\text {nd }}$ instar was almost similar to those obtained by Mondal (1975). The findings on morphometrics of hog-plum are supported by Uddin et al. (2014).

Table 1. Morphometrics of the different life stages and body appendages of hogplum beetle

\begin{tabular}{l|c|c|c|c}
\hline \multirow{2}{*}{\multicolumn{1}{c}{ Morphometric parameters }} & \multicolumn{2}{c|}{ Length $(\mathrm{mm})$} & \multicolumn{2}{c}{ Width $(\mathrm{mm})$} \\
\cline { 2 - 5 } & Mean & $\pm \mathrm{SE}$ & Mean & $\pm \mathrm{SE}$ \\
\hline Egg & 1.95 & 0.02 & 0.60 & 0.01 \\
$1^{\text {st }}$ instar & 2.51 & 0.18 & 0.72 & 0.00 \\
$2^{\text {nd }}$ instar & 8.27 & 0.20 & 1.54 & 0.05 \\
$3^{\text {rd instar }}$ & 16.02 & 0.23 & 2.31 & 0.04 \\
$4^{\text {th }}$ instar & 21.80 & 0.51 & 2.81 & 0.10 \\
Adult male (Width across thorax) & 11.96 & 0.15 & 6.10 & 0.05 \\
Adult female (Width across thorax) & 15.30 & 0.16 & 8.26 & 0.22 \\
Antennae & 7.42 & 0.20 & - & - \\
Fore leg & 9.20 & 0.23 & - & - \\
Middle leg & 9.50 & 0.24 & - & - \\
Hind leg & 11.70 & 0.15 & - & - \\
Fore wing & 12.38 & 0.16 & 5.30 & 0.14 \\
Hind wing & 16.10 & 0.26 & 7.85 & 0.41 \\
\hline
\end{tabular}

Weight of full grown larva, adult male and female of hog-plum beetle is presented in Figure 4. The mean weight of Full grown larva was $0.366 \pm 0.011 \mathrm{~g}$. The mean weight of adult male and female was $0.183 \pm 0.004 \mathrm{~g}$ and $0.274 \pm$ $0.005 \mathrm{~g}$, respectively. The adult male was lighter in weight than adult female. 


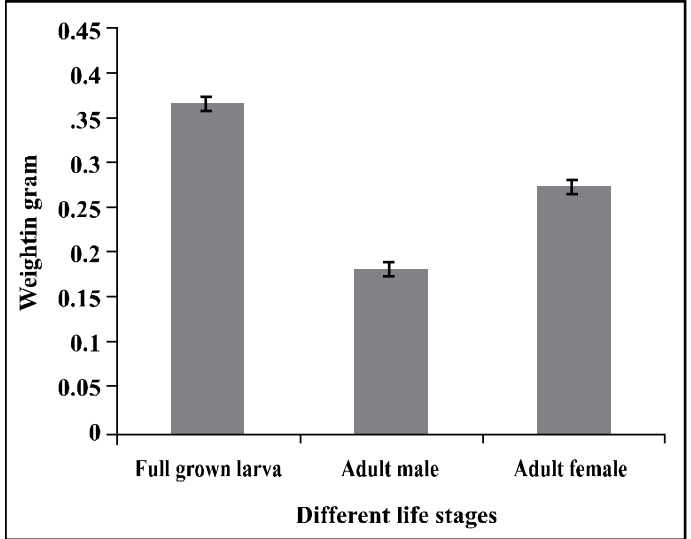

Fig. 4. Weight of Full grown larva, adult male and female of hog-plum beetle

From the findings of the present study it may be concluded that the maximum number of egg clusters was on leaf rachis and young stem compared to leaf. The female beetle lived longer than the male. The size of female beetle was larger than male. The hind pair of leg was longer compared to fore and mid pairs of legs. Hind wings were larger than fore wings.

\section{Acknowledgement}

The author is grateful to the University Grants Commission of Bangladesh for financial assistance to carry out the research project.

\section{References}

Ahmad, K. 1969. Minor fruits of East Pakistan. In: Flowers, fruits and vegetables. (ed. 2). Sharbajanin Granthalay, Government New Market, Dhaka. 344 Pp.

Baksha, M.W. 1997. Biology, ecology and control of amra defoliator, Podontia quaturdecimpunctata Linn. (Chrysomelidae: Coleoptera) in Bangladesh. Bangladesh J. Forest Sci. 26 (1): 43-46.

Howlader, M.A. 1993. Growth, development and survival of Podondia quaturdecempunctata L. (Chrysomelidae: Coleoptera) larvae on different parts of host plant. Bangladesh J. Zool. 21: 1-7.

Husain, M. and M. Ahmad. 1977. Notes on chrysomelid beetles (Coleoptera) of the Bangladesh Agricultural University area, Mymensingh. Bangladesh J. Zool. 5: 71-75.

Mondal, M.A. 1975. Studies on the biology and control of fourteen spotted leaf beetle, Podontia 14-punctata (Coleoptera: Chrysomelidae) on the hogplum. M.S. Thesis, Department of Entomology, Bangladesh Agricultural University, Mymensingh.

Sardar, M. A. and A. Mondal. 1983. Bio-ecology and chemical control of Podondia 14 punctata (Linn.) on hog plum. Indian J. Agric. Sci. 53 (8): 745-748.

Singh, P. and R.M. Misra. 1989. Bionomics of the ambara defoliator Podondia 14punctata Linn. (Coleoptera: Chrysomelidae). Indian Forester. 115 (12): 910-915.

Uddin, M.J., M.M.H. Khan, M.H. Rahman and M.A. Bakar. 2014. Biology and morphometrics of hogplum beetle, podontia 14-punctata 1. (chrysomelidae: coleoptera). J. Patuakhali Sci. and Tech. Univ. 5 (1): 71-82. 